\title{
Contribution to reducing uncertainties regarding the dry deposition velocities of fine aerosols: study case of a prairie (description of experimental methods and comparison with models)
}

\author{
O. Connan, D. Maro, D. Hébert, M. Rozet, B. Checiak \& L. Solier \\ Institute for Radiological Protection and Nuclear Safety, \\ Laboratoire de Radioécologie de Cherbourg-Octeville, \\ IRSN/DEI/SECRE, France
}

\begin{abstract}
In the context of environmental protection, the transfer of aerosols to vegetative canopies must be properly estimated, since aerosols constitute a preferential transport pathway for atmospheric pollution (bacteriological, chemical or radioactive). In order to properly assess the transport of pollutants, it is essential to accurately determine their dry deposition fluxes. Previous studies conducted around a nuclear site showed that the deposition prediction models do not yield an accurate representation of measured radionuclide activity (mainly ${ }^{106} \mathrm{Ru}$ ) in grasses, with observed discrepancies probably attributable to an underestimate of the dry deposition velocities. In addition, the literature mentions uncertainties in the order of two decades for the deposition velocities of particles larger than 1 $\mu \mathrm{m}$, and little experimental data is available for submicronic particles. In order to reduce these uncertainties and choose a suitable model, a series of experiments to measure the dry deposition velocities of aerosols has been scheduled for 2005 2007. This document presents the method used and the results obtained for a fine aerosol $(0.24 \mu \mathrm{m})$ dispersed over a prairie under neutral or unstable meteorological conditions. The technique used consists of generating a monodispersed fluorescein aerosol. The fluorescein concentration is measured in the grass and air by spectrofluorimetry and used to obtain the dry deposition velocities. A second approach using natural radioactivity $\left({ }^{214} \mathrm{~Pb}\right)$ and gamma spectrophotometry measurements has enabled the confirmation of the results obtained. The mean deposition velocities measured in this first series of experiments for a prairie-type substrate vary between 4 10-4 and 2 10-3 m.s-1. The comparison with the Slinn, Zhang and Wesely models shows that the first of these underestimates the deposition velocities by a factor of 5 to 20 and the other two more accurately represent the experimental measurements, with model/measurement discrepancies of generally less than 2 .
\end{abstract}

Keywords: deposition velocity, contaminant aerosol. 


\section{Introduction}

The atmospheric dispersion of pollutant elements (chemical, radioactive, bacteriological) discharged by industry in the form of gases or aerosols is an important transfer pathway towards the environment. Atmospheric dispersion involves physical phenomena (transport and diffusion) that interact with dry or wet deposition mechanisms. The deposition velocities depend on numerous parameters (precipitation characteristics in the case of wet depositions, shape and size of aerosols, meteorological and ground surface conditions, etc.). Studies on dry deposition have been conducted by the IRSN (Institute for Radiological Protection and Nuclear Safety) further to an incident in May 2001 causing the release of radionuclide ${ }^{106} \mathrm{Ru}-\mathrm{Rh}$ into the atmosphere by the Cogema spent fuel processing plant at La Hague (France). Differences were observed between the measured deposition velocities and those calculated by the models [1]. In the course of these studies, the dry deposition velocity at $700 \mathrm{~m}$ further to the incident was estimated at $5.710^{-2} \mathrm{~m} . \mathrm{s}^{-1}$, i.e., one order of magnitude greater than the apparent deposition velocity of $5.10^{-3} \mathrm{~m} . \mathrm{s}^{-1}$ typically employed in operational models. However, this deposition velocity, measured at a distance of $700 \mathrm{~m}$, did not explain the measured activities at greater distances. The conclusions of these studies show that in order to reproduce the depositions observed further to the incident, the deposition velocities of the atmospheric aerosols (i.e., granulometry close to $0.2 \mu \mathrm{m}$ ) must be taken into account along with the coagulation phenomena involved. Significant uncertainties remain concerning the deposition velocities of fine aerosols, since few experiments have been conducted for these types of aerosols, especially on-site. In the case of submicronic particles, deposition velocities vary between approximately $510^{-5}$ and $510^{-3} \mathrm{~m} \cdot \mathrm{s}^{-1}$ and are particularly dependent on meteorological and surface conditions [2]. The purpose of our work is to measure the dry deposition velocities of aerosols in the natural environment. We therefore plan to conduct a series of experiments with different aerosol granulometries and different meteorological and surface conditions so as to validate a suitable model. This initial study proposes experimental measurements to determine the dry deposition velocities of fine aerosols $(0.2-$ $0.3 \mu \mathrm{m})$. Although the aerosols released during previous nuclear accidents (Chernobyl, Thule) showed sizes ranging from 0.7 to $2 \mu \mathrm{m}$ [3], the granulometry of 0.2 to $0.3 \mu \mathrm{m}$ has been initially selected because it is representative of atmospheric aerosols and corresponds to the minimum efficiency of numerous filters used in industry [4]. Moreover, since it has been established that deposition velocities are minimal for aerosols with sizes between 0.1 and $1 \mu \mathrm{m}$, our results will yield the low values to be taken into account in the models. This document presents the method developed to experimentally measure the deposition velocity of an aerosol with granulometry of 0.2 to $0.3 \mu \mathrm{m}$ dispersed over a prairie-type substrate. 


\section{Experimental measurements}

\subsection{Principle}

A method to determine the deposition velocity of an aerosol has been developed using fluorescein (uranine) dispersed in the form of a dry aerosol and subsequently measured in the air and grass. The aerosol is generated with a given granulometry, and $\mathrm{SF}_{6}$ tracer gas is simultaneously emitted to determine the ATCs (atmospheric transfer coefficients) at each location where fluorescein concentration in the grass is to be measured. This method compensates the lack of systematic measurements of fluorescein concentration in the air (only two measurements per experiment). Micrometeorological measurements are taken in the exact location where the aerosol is generated. A diagram illustrating the procedure is provided in Figure 1. Aerosols are sampled on both sides of the wind axis along two radial lines R1 and R2 at distances of 10 to $30 \mathrm{~m}$. The aerosols in the air are collected by HVS (high volume samplers) at a rate of 30 $\mathrm{m}^{3} \cdot \mathrm{h}^{-1}$. For the aerosols deposited on the grass, we use grass squares of approximately $2500 \mathrm{~cm}^{2}$. These squares are cut on-site the day before and kept protected until the start of the experiment to prevent the retention of aerosols by water possibly present on grass leaves. Upon completion of the experiment, the grass is cut by hand over a measured surface and stored sheltered from light, at ambient temperature, until the subsequent conduction of the analysis in the hours that follow.

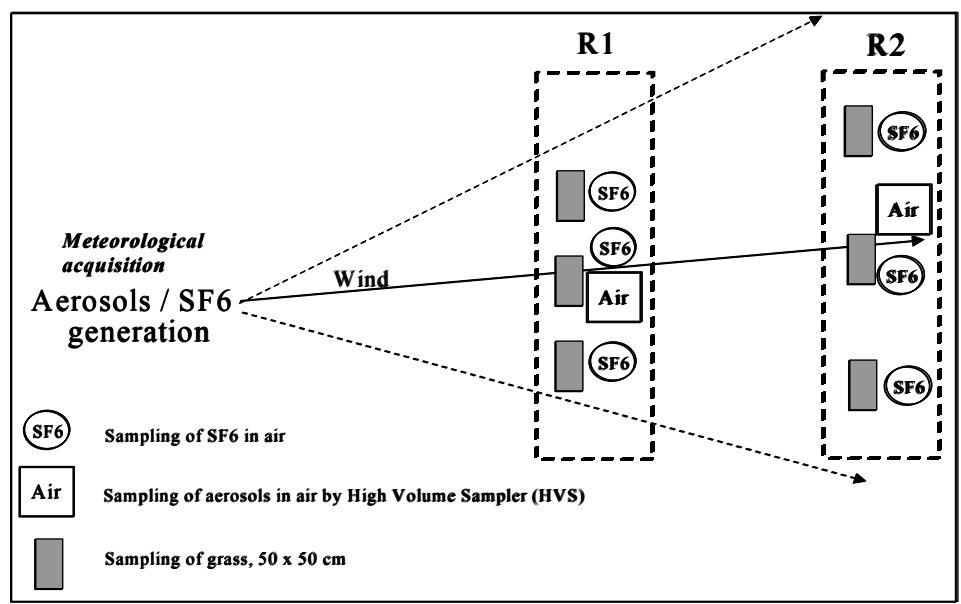

Figure 1: Basic diagram of the experiments.

\subsection{Aerosol and tracer gas generation}

The aerosol is generated using a fluorescein generator. The various air spray, dilution, filtering and drying modules are adjusted so as to obtain particles with a 
mean diameter about $0.20 \mu \mathrm{m}$ dry. The fluorescein aerosol is generated for 60 minutes. The system is properly calibrated (AFNOR NFX 44-011) and the aerosols emitted are controlled by an ELPI (Electric Low Pressure Impactor, DEKATI). The mass median diameter of the particles is $0.24 \mu \mathrm{m}$. The granulometric spectrum of the aerosol emitted is shown in Figure 2. Simultaneously with the emission of fluorescein $\left(30 \mathrm{mg} \cdot \mathrm{h}^{-1}\right), \mathrm{SF}_{6}$ tracer gas is also emitted. This gas is exclusively anthropogenic and therefore not present in the atmosphere. The system used consists of an $\mathrm{SF}_{6}$ bottle (Messer, France) connected to a mass flowmeter (Sierra 820). The emission is performed through the fluorescein aerosol emission pipe. The $\mathrm{SF}_{6}$ emission rate is fixed at $0.4 \mathrm{~g}$ per second.

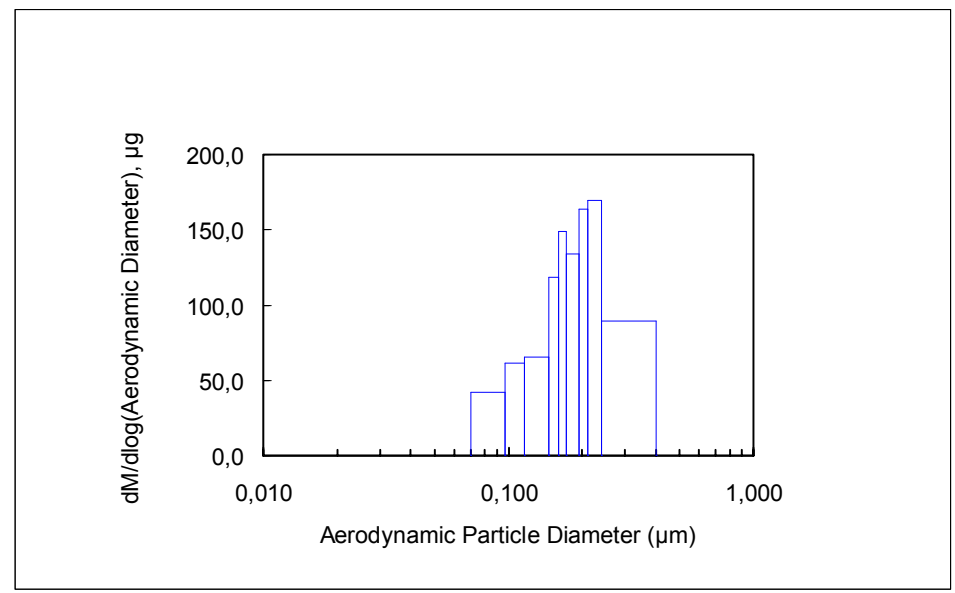

Figure 2: Distribution of the fluorescein aerosol particles emitted during the experiments, according to aerodynamic diameter. The Mass Median Diameter (MMD) and Geometric Standard Deviation (GSD) are $0.24 \mu \mathrm{m}$ and 1.73 , respectively.

\subsection{Fluorescein measurement}

The fluorescein measurement is performed using an UV spectrophotometer (Horiba Fluoromax-3). The excitation wavelength is fixed at $490 \mathrm{~nm}$ and emission is measured at $512 \mathrm{~nm}$. To measure the fluorescein concentration in the air, the filters are cut off and immerged in a water-ammonia solution with $\mathrm{pH} 9$ under mechanical agitation for 20 minutes. To measure the concentration in the grass, the same procedure is used, with manual agitation so as to not destroy the grass fragments. Prior to the measurement, the solutions are filtered at $0.2 \mu \mathrm{m}$.

\section{4 $\mathrm{SF}_{6}$ measurement}

Samples are taken in Tedlar bags, allowing for time-integrated sampling during the generation of the fluorescein aerosol. $\mathrm{SF}_{6}$ analyses are then performed by gas chromatography (AUTOTRAC, Lagus Applied Technology Inc.). 


\subsection{Acquisition of meteorological data}

Micrometeorological data is obtained from two sonic anemometers (Gill Research, $20 \mathrm{~Hz}$ ) installed in the experimentation site, one in the immediate proximity of the fluorescein generator, the other fixed to a $10 \mathrm{~m}$ telescopic mast. The measurement data is used to calculate various parameters so as to characterise the site, the frictional velocity $\mathrm{u}^{*}\left(\mathrm{~m} \cdot \mathrm{s}^{-1}\right)$, the Monin-Obukhov length (LMO) and the rugosity length zo $(\mathrm{cm})$.

\section{Experimental results}

\subsection{Experimentation site}

Measurements were initially taken in a field with an area of approximately 1000 $\mathrm{m}^{2}$, bounded by small slopes $(80$ to $120 \mathrm{~cm})$. Westerly and south-westerly winds prevail. The field is located near the Cogema spent fuel processing plant at La Hague (France). It was selected because it is characteristic of the environment surrounding the plant and therefore appropriate for studies on aerosol deposition from the plant.

\subsection{Meteorological conditions}

Experiments were conducted under neutral and unstable meteorological conditions (classes D and B, respectively, according to the Pasquill classification [5]) associated with weak winds of less than $2 \mathrm{~m} . \mathrm{s}^{-1}$ at ground level, a frictional velocity of less than $0.5 \mathrm{~m} . \mathrm{s}^{-1}$ and a rugosity length zo comprised between 8 and $30 \mathrm{~cm}$. These values are characteristic of non-cultivated prairie-type soils surrounded by slopes and rows of trees [6]. The mean meteorological data is shown in Table 1 below.

Table 1: $\quad$ Average meteorological parameters (ground level, 1m ref).

\begin{tabular}{ccccccc}
\hline Date & $\begin{array}{c}\mathbf{T}\left({ }^{\circ} \mathbf{C}\right) \\
(\mathbf{R H})\end{array}$ & $\begin{array}{c}\mathbf{V} \\
\left(\mathbf{m . s}^{-\mathbf{1}}\right)\end{array}$ & $\begin{array}{c}\mathbf{1} / \mathbf{L M O} \\
\left(\mathbf{m}^{-\mathbf{1}}\right)\end{array}$ & $\begin{array}{c}\mathbf{Z o} \\
(\mathbf{c m})\end{array}$ & $\begin{array}{c}\mathbf{U}^{*} \\
\left(\mathbf{m} . \mathbf{s}^{-1}\right)\end{array}$ & $\begin{array}{c}\text { Stability } \\
\text { class }\end{array}$ \\
\hline $09 / 09 / 05$ & $18.2(84 \%)$ & 1.5 & -0.002 & 12.5 & 0.21 & $\mathrm{D}$ \\
$28 / 09 / 05$ & $13.5(76 \%)$ & 1.3 & -0.003 & 23.7 & 0.40 & $\mathrm{D}$ \\
$11 / 10 / 05$ & $13.5(84 \%)$ & 1.3 & -0.003 & 21.6 & 0.30 & $\mathrm{D}$ \\
$11 / 10 / 05$ & $13.5(80 \%)$ & 1,4 & -0.003 & 30.1 & 0.48 & $\mathrm{D}$ \\
$09 / 12 / 05$ & $8.5(75 \%)$ & 1.3 & -0.066 & 8.5 & 0.17 & $\mathrm{~B}$ \\
\hline
\end{tabular}

\subsection{Dry deposition velocities of aerosols}

\subsubsection{Calculation principle: Fluorescein method}

The dry deposition velocity of fluorescein $\left(\mathrm{m}^{-1} \mathrm{~s}^{-1}\right)$ is the quotient of the dry deposition flux at ground level $\left(\mathrm{g} \cdot \mathrm{m}^{-2} \cdot \mathrm{s}^{-1}\right)$ divided by the atmospheric concentration at ground level $\left(\mathrm{g} \cdot \mathrm{m}^{-3}\right)$, as expressed by equation (1): 


$$
\text { Vd }=\frac{\text { FluoGrass }}{\text { FluoAir }}
$$

- FluoGrass is the deposition flux of fluorescein in grass $\left(\mathrm{g} \cdot \mathrm{m}^{-2} \cdot \mathrm{s}^{-1}\right)$

- FluoAir is the atmospheric concentration of fluorescein $\left(\mathrm{g} . \mathrm{m}^{-3}\right)$

- Vd is the dry deposition velocity $\left(\mathrm{m} \cdot \mathrm{s}^{-1}\right)$.

Since it is physically impossible to measure the fluorescein concentration in the air above each measurement point in the grass, we have estimated the concentration values in the air based on two HVS measurement points (see Fig. 1) and $\mathrm{SF}_{6}$ measurements assigned to each grass sample, allowing us to calculate the ATCs (atmospheric transfer coefficients) and thereby deduce the fluorescein concentration values at all points. The ATC is expressed by equation (2):

$$
A T C=\frac{\int_{t 0}^{t 1} X(M, t) \cdot d t}{\int_{t^{\prime} 0}^{t^{\prime} 1} q(t) \cdot d t}
$$

- X(M,t): $\mathrm{SF}_{6}$ concentration $\left(\mathrm{m}^{3} \cdot \mathrm{m}^{-3}\right)$, measured at point $\mathrm{M}$

- $\mathrm{q}(\mathrm{t}): \mathrm{SF}_{6}$ release rate, in $\mathrm{m}^{3} \cdot \mathrm{s}^{-1}$

- $\mathrm{t}_{0}{ }_{0}, \mathrm{t}_{1}$ : Start and end times for source emission, in $\mathrm{s}$

$-\mathrm{t}_{0}, \mathrm{t}_{1}$ : Start and end times for measurement, in $\mathrm{s}$

The results from our first experiments are provided in Table 2, for an aerosol of $0.24 \mu \mathrm{m}$. The deposition velocities vary from $410^{-4}$ to $210^{-3} \mathrm{~m} . \mathrm{s}^{-1}$, depending on the conditions.

Table 2: $\quad$ Dry deposition velocity $\left(\mathrm{m} . \mathrm{s}^{-1}\right)$ for an aerosol of $0.24 \mu \mathrm{m}$.

\begin{tabular}{cccc}
$\begin{array}{c}\text { Date and no. } \\
\text { of experiment }\end{array}$ & $\mathrm{Vd}-$ Fluorescein $\left(\mathrm{m} . \mathrm{s}^{-1}\right)$ & $\begin{array}{c}\text { Stability } \\
\text { Class }\end{array}$ & $\mathrm{Vd}-{ }^{214} \mathrm{~Pb}\left(\mathrm{~m}^{-1} \mathrm{~s}^{-1}\right)$ \\
\hline $09 / 09 / 05: 1 \mathrm{a}$ & $210^{-3} \pm 310^{-4}$ & $\mathrm{D}$ (neutral) & \\
$09 / 09 / 05: 1 \mathrm{~b}$ & $110^{-3} \pm 710^{-4}$ & $\mathrm{D}$ (neutral) & \\
$28 / 09 / 05: 2 \mathrm{a}$ & $110^{-3} \pm 910^{-5}$ & $\mathrm{D}$ (neutral) & \\
$28 / 09 / 05: 2 \mathrm{~b}$ & $210^{-3} \pm 110^{-4}$ & $\mathrm{D}$ (neutral) & \\
$11 / 10 / 05: 3 \mathrm{a}$ & $110^{-3} \pm 210^{-4}$ & $\mathrm{D}$ (neutral) & \\
$11 / 10 / 05: 3 \mathrm{~b}$ & $910^{-4} \pm 310^{-4}$ & $\mathrm{D}$ (neutral) & \\
$11 / 10 / 05: 4 \mathrm{a}$ & $110^{-3} \pm 210^{-4}$ & D (neutral) & $1.910^{-3} \pm 5.710^{-4}$ \\
$11 / 10 / 05: 4 \mathrm{~b}$ & $110^{-3} \pm 610^{-4}$ & D (neutral) & \\
$09 / 12 / 05: 5 \mathrm{a}$ & $410^{-4} \pm 210^{-4}$ & B (unstable) & \\
\hline
\end{tabular}




\subsubsection{Method validation: comparison with ${ }^{214} \mathrm{~Pb}$ method}

In order to validate our method, we have compared the results obtained with a method taking into account natural radioactivity $\left({ }^{214} \mathrm{~Pb}\right.$ measurement in air and grass) as a dry deposition tracer [7]. Given the short half-life of this element (26.8 minutes), the measured activity in the grass can be considered as corresponding to the instantaneous deposition of aerosols from the atmosphere. The principle adopted therefore consists of measuring the ${ }^{214} \mathrm{~Pb}$ activity deposited on a filter $\left({ }^{214} \mathrm{~Pb}\right.$ activity in air, via HVS sampling for several hours) and the ${ }^{214} \mathrm{~Pb}$ activity in grass at the same location. Air sampling was performed for 3 hours. The atmospheric aerosols in these experiments had a Mass Median Diameter (MMD) of $0.27 \mu \mathrm{m}$ with a geometric standard deviation (GSD) of 1.84 (Fig. 3), i.e., very close to the granulometry of $0.24 \mu \mathrm{m}$ and standard deviation of 1.76 associated with the emitted fluorescein aerosol (Fig. 1). ${ }^{214} \mathrm{~Pb}$ measurements on the filters and grass were performed by gamma spectrometry. The dry deposition velocity for ${ }^{214} \mathrm{~Pb}$ is expressed by equation (3):

$$
V d=\frac{{ }^{214} \mathrm{~Pb}(\text { grass })}{{ }^{214} \mathrm{~Pb}(\text { air })} \times \frac{1}{t}
$$

where ${ }^{214} \mathrm{~Pb}$ (grass) and ${ }^{214} \mathrm{~Pb}$ (air) are the ${ }^{214} \mathrm{~Pb}$ activities in grass $\left(\mathrm{Bq} \cdot \mathrm{m}^{-2}\right.$ ) and air $\left(\right.$ Bq. $\mathrm{m}^{-3}$ ), taking into account the radioactive decay (half-life $=26.8 \mathrm{~min}$ ) and the masses and volumes sampled and sampling time- $(\mathrm{t}$ in s) corrected to obtain velocity values. This method yields a dry deposition velocity of $1.910^{-3} \mathrm{~m} \cdot \mathrm{s}^{-1}$, to be compared with the value of $110^{-3} \mathrm{~m} \cdot \mathrm{s}^{-1}$ obtained simultaneously with the fluorescein method (experiment of 11/10/05, Table 2).

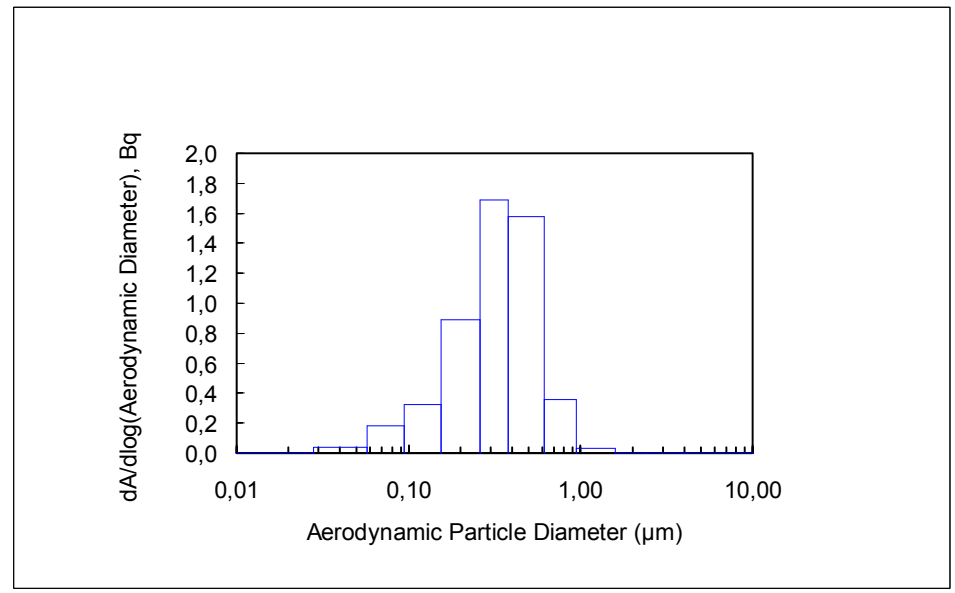

Figure 3: Distribution of atmospheric aerosol during ${ }^{214} \mathrm{~Pb}$ measurement experiments of 11/10/05. The Mass Median Diameter (MMD) and Geometric Standard Deviation (GSD) are $0.27 \mu \mathrm{m}$ and $1.84 \mu \mathrm{m}$, respectively. 


\subsubsection{Discussion}

The results of this study, conducted in the same site for an aerosol of $0.24 \mu \mathrm{m}$, indicate an average deposition velocity of $0.13 \mathrm{~cm} \cdot \mathrm{s}^{-1}$ under neutral meteorological conditions and $0.04 \mathrm{~cm} \cdot \mathrm{s}^{-1}$ under unstable meteorological conditions. Our results are slightly higher than those presented by Sehmel [8], which indicate $\mathrm{Vd}$ values of 0.03 to $0.05 \mathrm{~cm} \cdot \mathrm{s}^{-1}$ for a granulometry of 0.2 to 0,3 $\mu \mathrm{m}$ under atmospheric conditions and with $\mathrm{u}^{*}$ varying from 20 to $30 \mathrm{~cm} \cdot \mathrm{s}^{-1}$ and zo $=10 \mathrm{~cm}$, which is close to our experimental conditions. Zhang et al [9] present values ranging from $<0.05$ to $0.18 \mathrm{~cm} . \mathrm{s}^{-1}$ for a grass-type substrate and granulometries varying from 0.05 to $1 \mu \mathrm{m}$. Our measurements yield deposition values perfectly consistent with those in the literature, thus confirming the method. For neutral meteorological conditions, we obtain deposition velocities in the 'high' range of values published. Surprisingly, our only experiment under more unstable meteorological conditions $(09 / 12 / 05)$ yielded a lower deposition velocity than under neutral conditions. In strictly meteorological terms, this experiment was conducted under instable conditions, but with lower field rugosity parameters $\left(\mathrm{u}^{*}, \mathrm{zo}\right)$ than in the previous experiments. These observations show the necessity to conduct a complete parametric study, for variable ranges of $\mathrm{u}^{*}$ and zo values.

\section{Comparison with Slinn, Zhang and Wesely models}

We have compared our results with three models conventionally used to obtain the dry deposition velocities of aerosols. The first is the Slinn model [10], which yields deposition velocities for different particle sizes and is applicable to the vegetative canopy. The second is the Zhang et al model [9], which yields the deposition velocities for different types of substrates (prairie, urban environment, ocean, etc.) and different meteorological conditions, using parameter tables based on the conditions selected. These two models are founded on similar physical principles, taking into account Brownian diffusion, sedimentation, impaction, interception and rebound principles. The Zhang model uses the physical basis of the Slinn model, simplifying the parameters of the deposition processes and including a term to take into account the influence of humidity on the particles. The last model with which we have compared our measurements is the Wesely et al empirical model [11], which is based on studies of submicronic sulphate aerosol deposition on grass. This model does not take the sedimentation velocity into account and mainly reflects the influence of the atmospheric stability on the deposition, based on the $\mathrm{u}^{*}$ and LMO values. We have compared our measurements with the results obtained from these models. For the Slinn and Zhang models, we have used parameters corresponding to the grass-type substrate. The meteorological parameters measured by us $\left(\mathrm{u}, \mathrm{LMO}, \mathrm{zo}, \mathrm{u}^{*}\right)$ have been taken into account in these calculations. The comparison between our measurements and the models is summarised in Table 3. It appears that the Zhang model best reproduces our experimental results. In average, the Slinn model underestimates the deposition velocities by a factor of 10 . The Wesely model, based only on micrometeorological influences, shows little deviation 
from our measurements, underestimating them by a factor of 1 to 5 under neutral conditions. Given the uncertainties involved, the results of the Zhang and Wesely models are encouraging, particularly those of the Zhang model, which does not underestimate the deposition velocities and is therefore to be privileged for operational purposes.

Table 3: Dry deposition velocities, comparison with models for aerosols of $0.24 \mu \mathrm{m}$ and prairie grass substrate (measurement/model ratios shown in brackets).

\begin{tabular}{cllll}
\hline Date & \multicolumn{1}{c}{ Vd $\left(\mathrm{m} . \mathrm{s}^{-1}\right)$} & Vd Slinn $\left({\left.\mathrm{m} . \mathrm{s}^{-1}\right)}\right.$ & $\mathrm{Vd}$ Zhang $\left(\mathrm{m} . \mathrm{s}^{-1}\right)$ & $\mathrm{Vd}$ Wesely $\left(\mathrm{m} . \mathrm{s}^{-1}\right)$ \\
\hline $09 / 09 / 05$ & $110^{-3}-210^{-3}$ & $910^{-5}(11-22)$ & $110^{-3}(1-2)$ & $410^{-4}(2.5-5)$ \\
$28 / 09 / 05$ & $110^{-3}-210^{-3}$ & $210^{-4}(5-10)$ & $310^{-3}(0.3-0.6)$ & $810^{-4}(1.3-2.5)$ \\
$11 / 10 / 05$ & $910^{-4}-110^{-3}$ & $110^{-4}(9-10)$ & $210^{-3}(0.5)$ & $610^{-4}(1.5-1.7)$ \\
$11 / 10 / 05$ & $110^{-3}$ & $210^{-4}(5)$ & $310^{-3}(0.3)$ & $910^{-4}(1.1)$ \\
$09 / 12 / 05$ & $410^{-4}$ & $710^{-5}(6)$ & $110^{-3}(0.4)$ & $310^{-3}(0.1)$ \\
\hline
\end{tabular}

\section{Conclusion}

Experimental measurements of the dry deposition velocities of aerosols with granulometry of $0.24 \mu \mathrm{m}$ have been conducted on grass by measuring the dry deposition velocity of a fluorescein aerosol. The deposition velocity varies from $410^{-4}$ to $210^{-3} \mathrm{~m} . \mathrm{s}^{-1}$, depending on the atmospheric conditions. The method has been validated by comparison with a method employing the ${ }^{214} \mathrm{~Pb}$ 'natural' radionuclide and we have confronted our results with those of 3 models (Slinn, Zhang, Wesely). The results are promising and similar experiments under different atmospheric conditions and with other aerosol granulometries will be conducted so as to obtain experimental values covering a broad observation range.

\section{Acknowledgements}

The authors wish to thank COGEMA for his contribution in this program.

\section{References}

[1] Maro, D., Boulaud, D., Copalle, A., Germain, P., Hébert, D. \& Tenailleau L. Validation of dry deposition models for submicronic - micronic aerosols. Proceedings of $9^{\text {th }}$ Int Conf HARMO, Garmisch, pp. 89-94, 1-4 June 2004.

[2] Pal Arya, S., Air Pollution Meteorology and Dispersion, (chapter 10) Near-neutral Boundary Layers, pp. 188-212, 1999.

[3] Andersson, K.G., Roed, J., Byrne, M.A. \& Hessio H., Deposition of contaminant aerosol on human skin. Journal of Environmental Radioactivity, 85, pp. 182-195, 2006. 
[4] Hinds W.C., Aerosol technology : properties, behavior and measurement of airbone particles, (chapter 9) Filtration, pp. 182-205, 1999.

[5] Tagliazucca, M. \& Nanni T., An atmospheric diffusion classification scheme based on the kazanski-monin stability parameter. Atmospheric environment, 17 (11), pp.2205-2211, 1983.

[6] Schnelle, K.B. \& Dey P.R., (eds). Atmospheric dispersion modeling compliance guide, McGraw-Hill, 2000.

[7] Bondietti, E.A., Hoffman, F.O. \& Larsen I.L., Air to vegetation transfer rates of natural submicron aerosols, Journal of Environmental Radioactivity, 1, pp. 5-27, 1984.

[8] Sehmel, G.A., Particle and gas dry deposition : a review. Atmospheric environment, 14, pp.983-1011, 1980.

[9] Zhang, L., Gong, S., Padro, J. \& Barrie L., A size-segregated particle dry deposition scheme for an atmospheric aerosol module. Atmospheric environment, 35, pp.549-560, 2001.

[10] Slinn, W.G.N., predictions for particle deposition to vegetative canopies. Atmospheric Environment., 16, 7, pp. 1785-1794, 1982.

[11] Wesely, M.L., Cook, D.R., Hart, R.L. \& Speer R.E, Measurements and parametrization of particle sulfur deposition over grass. Journal of Geophysical Research, 90, pp 2131-2143, 1985. 